\title{
Diálogos fora de esquadro: o controle das agências reguladoras pelo Tribunal de Contas da União
}

\author{
Outlier conversations: Oversight of the \\ Federal Court of accounts over independent \\ regulatory agencies
}

\section{Floriano de Azevedo Marques Neto \\ Juliana Bonacorsi de Palma}

Resumo: O presente artigo busca analisar os fatores determinantes da complexidade do controle das Agências Reguladoras pelo Tribunal de Contas da União com competências operacionais, notadamente o fato de ambas as instituições serem estranhas ao projeto constituinte. Desse modo, pretende caracterizar essa dinâmica de controle, aqui reconhecida como "diálo-

1 Possui Graduação em Direito (1990), Doutorado em Direito (1999), e Livre-Docência em Direito (2008), todos pela Universidade de São Paulo. Atualmente é Diretor e Professor Titular do Departamento de Direito de Estado da Faculdade de Direito da USP.

2 Doutora (2014) e Mestre (2010) pela Faculdade de Direito da Universidade de São Paulo. Professora da FGV Direito SP nos programas de graduação, mestrado profissional e especialização - FGVLaw. Coordenadora do Grupo Público da FGV Direito SP e colaboradora da Escola de Formação Pública, da qual foi aluna (2004). 
gos fora de esquadro", a partir das diferentes leituras doutrinárias sobre os fundamentos de competência e a medida do controle, bem como de trabalho empírico que confere os contornos práticos deste controle. Ao final, propõe iniciativas de reforma normativa para um desenho melhor estruturado e previsível do controle das Agências Reguladoras pelo TCU.

Palavras-chave: Agências Reguladoras - Tribunal de Contas da União - controle da regulação - Constituição - reforma normativa

Abstract: this paper tackles the key factors for a complex oversight dynamic between Independent Regulatory Agencies and Federal Court of Accounts, mainly the fact that both of them were strangers to the Constitution drafters. Therefore, the named "outlier oversight" is the main study object, considering scholars discussion as well as empirical studies which provide a practical perception of these dynamics. In the end, the paper presents alternatives for reconstruction of the Federal Court of Accounts' oversight of Independent Regulatory Agencies for more rationality and legal certainty.

Keywords: Independent Regulatory Agencies Federal Court of Accounts - regulation oversight Constitution - normative drafts

\section{Introdução}

Ojogo da governabilidade é complexo. Há uma plêiade de atores, dinâmicas e variáveis que definem a capacidade de o Executivo tomar decisões efetivas e, assim, satisfazer as finalidades públicas definidas em regras de competência. $\mathrm{O}$ estudo desses fatores varia de agenda para agenda de pes- 
quisa, considerando a abordagem escolhida, mas um pressuposto é comum a todas as linhas: o Direito importa. Isso porque são as fontes jurídicas que conformam todo o arranjo no qual se estrutura a governabilidade, ou seja, as "regras do jogo da governabilidade" são ditadas pelo Direito. A essa matriz formal, originária na estruturação da dinâmica entre os Poderes, outros elementos se acoplam para determinar o grau de governabilidade em um determinado contexto e momento histórico, elementos esses de natureza política, econômica, ideológica, cultural etc.

Em Estados cuja Constituição desempenha um papel central na condução política, como é o caso do Brasil, as regras do jogo da governabilidade são primacialmente definidas na própria Constituição e, a posteriori, na hermenêutica constitucional. Não por outra razão os precedentes do Supremo Tribunal Federal têm delineado os contornos da separação de Poderes, especialmente nos casos em que a Corte se debruçou sobre situações concretas que desafiavam o papel institucional de cada Poder. No desenho das instituições de Estado - aqui considerando não apenas os três Poderes, mas também o Ministério Público e o Tribunal de Contas -, a Constituinte buscou estabelecer a missão de cada qual em um novo cenário democrático. Para um novo panorama, novas atribuições e instituições reconfiguradas.

Fato é que nesses 30 anos de Constituição brasileira as instituições mostraram-se vivas e adaptáveis. As competências deslocam-se conforme a reputação institucional, crises econômicas e contextos de sensibilidade política ou de comoção popular. Na mesma trilha vão a dotação orçamentária, os bons quadros de pessoal e tantos outros elementos centrais à definição das entidades de Estado. Uma traição ao projeto da Constituinte? Aqui a resposta pode variar de acordo com a visão que se tenha da vinculação dos novos 
tempos às origens da nossa Constituição, mas o referencial de análise se encontra no texto constitucional.

Neste artigo argumentamos que duas instituições de primeira grandeza para o Direito Administrativo ficaram de fora do projeto Constituinte de construção institucional e, principalmente por essa razão, terminam por estabelecer um diálogo fora de esquadro. O TCU operacional e as Agências Reguladoras são estranhos desconhecidos da Constituinte. Porém, são reais e interagem. O diálogo institucional entre $\mathrm{TCU}^{3}$ e Agências Reguladoras é aqui caraterizado como "fora de esquadro", pois embora o controle se dê dentro da ordem constitucional, jamais o enquadramento constitucional foi arquitetado considerando a dinâmica de controle entre uma Agência Reguladora dotada de autonomia e independência frente ao chefe do Poder Executivo e um TCU com competência operacional. Isso traz consequências concretas à dinâmica de controle para além da natural complexidade e incerteza jurídica.

\section{Agências Reguladoras e Tribunal de Contas: instituições estranhas à Assembleia Nacional Constituinte}

A conformação atual do Estado Democrático de Direito brasileiro resulta diretamente das decisões político-institucionais tomadas no contexto da passagem do regime de exceção ditatorial para a abertura democrática. As mais determinantes dessas decisões foram tomadas pela Assembleia Nacional Constituinte e traduzidas como projetos na então nova Constituição promulgada em 1988.

3 Neste ponto do artigo em diante, indica-se o TCU investido de competências operacionais simplesmente como TCU. 
A expressão "projeto constitucional" mostra-se adequada para exprimir o inédito caráter experimentalista da Constituição. Se é verdade que fórmulas consagradas no constitucionalismo brasileiro encontram-se reproduzidas em diversos preceitos da vigente Constituição, também é verdade que houve um sentimento de ruptura com o establishment para redesenhar o Estado e a sociedade. Para tanto, a estratégia seria a previsão de direitos, deveres regulamentares, desenhos institucionais e novas dinâmicas de interação entre atores no texto constitucional. Assim, a Constituição se transformaria no mais efetivo motor de transformação social ${ }^{4}$. O que de fato impulsionou os Constituintes a optarem pelo conjunto de projetos que hoje conhecemos é um capítulo à parte. Fiquemos aqui com os dois protagonistas do objeto do nosso estudo: as Agências Reguladoras Independentes e o Tribunal de Contas da União.

A Assembleia Nacional Constituinte tomou como referência a estrutura de organização burocrático-administrativa disciplinada no Decreto-Lei n. ${ }^{\circ}$ 200/67 para disciplinar a Administração Pública brasileira. Adota-se, assim, o modelo de Executivo Unitário, cabendo ao "chefe" do Poder Executivo a disciplina hierárquica de seus órgãos subalternos e o controle de seus entes personificados, como autarquias e empresas estatais. O chefe do Executivo corresponde exatamente ao ponto de coesão e uniformidade do Poder Público, com dois pressupostos bastantes claros: (i) protagonismo decisório do chefe do Executivo, que detém o poder constitucional de proferir a primeira e a última decisão, e

4 Para uma exposição realista das forças de ação na Assembleia Nacional Constituinte e crítica à idealização da Constituição, dado que vários de seus preceitos terminaram por prestigiar categorias e grupos de interesse específicos, cf. SuNDFELD, 2014, p. 341-351. Especificamente analisando a influência da categoria do Judiciário no processo constituinte, cf. CARVALHO, 2017, p. 31-73. 
(ii) plena capacidade de organização administrativa pelo chefe do Poder Executivo.

Na qualidade de representante eleito pelo povo, o chefe do Poder Executivo tem a primazia decisória de políticas públicas, estratégias governamentais, alocação de recursos e todas as demais expressões da função administrativa, desde a mais complexa até a mais comezinha. Porém, na medida em que sozinho o chefe do Poder Executivo não daria cabo de suas atribuições, fazem-se necessários auxiliares para implementar as suas decisões ${ }^{5}$. Trata-se de agentes públicos de primeiro escalão, como Ministros e Secretários, até os agentes públicos de linha de frente ${ }^{6}$, cujo conjunto conforma uma Administração Pública piramidal de inspiração bonapartista ${ }^{7}$. Por mecanismos de controle interno ${ }^{8}$, seria garantida a vontade decisória do chefe do Poder Executivo, podendo até mesmo substituir a decisão de seu auxiliar para prevalecer a sua orientação do que seja o interesse público no caso concreto.

O pressuposto de plena capacidade de organização administrativa também é recolhido do Decreto-Lei n. ${ }^{\circ}$ 200/679 ,

5 É a redação do art. 76 da Constituição Federal: “art. 76. O Poder Executivo é exercido pelo Presidente da República, auxiliado pelos Ministros de Estado". Cf. art. $1^{\circ}$ do Decreto-Lei n. ${ }^{\circ}$ 200/67: "art. $1^{\circ}$ O Poder Executivo é exercido pelo Presidente da República auxiliado pelos Ministros de Estado".

6 Cf. art. $2^{\circ}$ do Decreto-Lei n. ${ }^{\circ}$ 200/67: "art. $2^{\circ}$ O Presidente da República e os Ministros de Estado exercem as atribuições de sua competência constitucional, legal e regulamentar com o auxílio dos órgãos que compõem a Administração Federal".

7 Sobre a conformação da Administração Pública brasileira em uma estrutura piramidal, cf. BinENBOJM, 2006, p. 239-261.

8 Cf. art. 26 do Decreto-Lei n. ${ }^{\circ}$ 200/67.

9 Cf. art. $3^{\circ}$ do Decreto-Lei n. ${ }^{\circ}$ 200/67: "art. $3^{\circ}$ Respeitada a competência constitucional do Poder Legislativo estabelecida no artigo 46, inciso II e IV, da Constituição, o Poder Executivo regulará a estruturação, as atribuições e funcionamento do órgãos da Administração Federal. (Redação dada pelo Decreto-Lei n ${ }^{\circ}$ 900, de 1969)". 
expressados pela Assembleia Nacional Constituinte no art. 84, VI, autorizando o chefe do Poder Executivo (federal) a dispor sobre a organização e o funcionamento da Administração Pública ${ }^{10}$. Redigido de forma ampla e abrangente, o preceito constitucional reforçaria a capacidade administrativa de organização interna de seus órgãos e entes, a distribuição de competências e os procedimentos para tomada de decisão por seus auxiliares. Reconhecidas as reservas de lei, como para a criação de autarquias ou para criação de cargos públicos, seria amplíssima a capacidade de organização administrativa mediante Decreto. Mesmo nas hipóteses de reserva de lei em matéria de organização administrativa, a Assembleia Nacional Constituinte fixou iniciativa privativa do chefe do Poder Executivo (federal) para, dentre outros, dispor sobre: a criação de órgãos, funções ou empregos públicos; o aumento remuneratório dessas carreiras; servidores públicos, inclusive suas prerrogativas como estabilidade e plano de aposentadoria; e criação, estruturação e atribuições dos Ministérios e órgãos da administração pública ${ }^{11}{ }^{12}$.

10 Esta era a redação original do art. 84, inc. VI, da Constituição Federal: "art. 84. Compete privativamente ao Presidente da República: (...) VI- dispor sobre a organização e o funcionamento da administração federal, na forma da lei". Nova redação foi dada ao preceito pela Emenda Constitucional n. ${ }^{\circ}$ 32, de 2001, caracterizando o decreto autônomo para organização e funcionamento da Administração, desde que não incorra em aumento de despesas ou em extinção de órgãos públicos, e para extinção de funções ou cargos públicos vagos. Isso conferiria maior autonomia de organização administrativa ao chefe do Poder Executivo frente à redação original do art. $61, \S 1^{\circ}$, inc. II, $e$, que também foi alterado pela referida Emenda Constitucional para fazer alusão à nova redação do art. 84, inc. VI, da Constituição.

11 A redação original do art. $61, \S 1^{\circ}$, inc. II, e, foi alterada pela Emenda

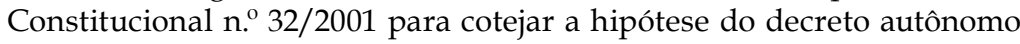
no art. 84, inc. VI, também por ela alterado. Eis a redação final do preceito: “e) criação e extinção de Ministérios e órgãos da administração pública, observado o disposto no art. 84, VI; (Redação dada pela Emenda Constitucional $n^{\circ} 32$, de 2001)".

12 Cf. art. $61, \S 1^{\circ}$, da Constituição Federal. 
Em síntese, a Assembleia Nacional Constituinte estabeleceu um modelo de Administração Pública centrado no chefe do Poder Executivo, com superioridade perante órgãos, entidades e agentes públicos - seus auxiliares -, dada a atribuição constitucional de protagonismo decisório e amplas competências de organização administrativa. $O$ modelo de Agências Reguladoras não foi debatido pela Assembleia Nacional Constituinte. Na verdade, a experiência ainda centrada em países filiados à common law ainda não era conhecida no Brasil.

A criação de Agências Reguladoras na década de 1990 desafia os pressupostos tomados pela Assembleia Nacional Constituinte, mas não caracteriza qualquer inconstitucionalidade, especialmente diante da expressa previsão constitucional dessas entidades ${ }^{13}$. Na verdade, a ninguém hoje ocorreria questionar a constitucionalidade das Agências Reguladoras com autonomia e independência frente ao chefe do Poder Executivo ${ }^{14}$. Porém, é fato, elas

13 Há duas menções expressas às Agências Reguladoras Independentes na Constituição Federal inseridas em 1995. A Emenda Constitucional n. ${ }^{\circ}$ 8/95 previu "a criação de um órgão regulador" para a disciplina, fiscalização e enforcement dos serviços de telecomunicações, doravante liberalizados,

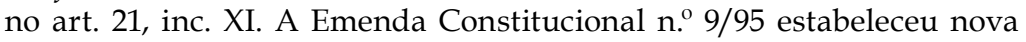
reserva de lei para dispor sobre as condições de contratação de empresas estatais ou privadas para a exploração dos serviços relacionados a Petróleo, incumbindo também a esta Lei prever "a estrutura e atribuições do órgão regulador do monopólio da União" (art. 177, §2 , inc. III). As novas previsões ensejariam, respectivamente, a criação da ANATEL e da ANP. Importa salientar que a noção de regulação não é estranha ao Direito brasileiro e à própria Constituinte. O art. 174, caput, da Constituição Federal faz expressa referência da função regulatória do Estado ao considerá-lo um "agente normativo e regulador da atividade econômica".

14 Embora a questão sobre a constitucionalidade das Agências Reguladoras seja hoje datada, fato que no contexto da reforma regulatória brasileira o debate se colocou intensamente. Para mais elementos do debate sobre a constitucionalidade das Agências Reguladoras, cf. MARques Neto, 2009, p. 28-35. O debate sobre a constitucionalidade das Agências Reguladoras 
funcionam dentro de um feixe de normas constitucionais desenhado à luz do Decreto-Lei n. ${ }^{\circ}$ 200/67, tomando como paradigma o modelo de Executivo Unitário, quando caracterizam a Administração Pública Policêntrica ${ }^{15}$. Em termos práticos, neste modelo se reconhece a existência de órgãos e entes administrativos, notadamente de capacidade técnica, cujas leis lhe conferem autonomia e independência, afastando as regras típicas do Executivo Unitário na medida em que o papel do chefe do Poder Executivo nessa seara é diminuto.

No que tange ao desenho do controle público pela Assembleia Nacional Constituinte, constata-se, de um modo geral, que as competências controladoras se alargaram frente a um cenário de desconfiança no Poder Público, então a representação mais caricata do Governo de exceção. Fator igualmente decisivo foi a presença de grupos representativos das categorias controladoras zelosos na Constituinte para garantir direitos e privilégios no texto constitucional uma estratégia interessante, dado que a um só tempo lhes conferiria status burocrático e tornaria mais difícil suprimi-los frente a uma simples lei ordinária ${ }^{16}$. Essas categorias também

é hoje superado, considerando o posicionamento do STF no leading case ADIN contra Lei Geral de Telecomunicações - LGT (ADI-MC 1.668-5), julgado pelo Supremo ainda no calor do debate em 1998, de reconhecer a constitucionalidade do modelo de autoridades administrativas independentes no Brasil. Além deste precedente, vários outros julgados do STF envolvendo atividades regulatórias de Agências Reguladoras partiam do mesmo pressuposto, expressamente apresentado ou não: o da constitucionalidade do modelo de Agências Reguladoras no Brasil, com plena autonomia e independência nos termos de suas leis de criação.

15 Cf. Binenbojm, 2006, p. 239-261.

16 SundFeld relata como o Poder Judiciário assegurou uma verdadeira "lei de organização judiciária nacional" no texto da Constituição e como o Supremo Tribunal Federal não apenas terminou o processo constituinte com suas competências de Corte Constitucional e órgão jurisdicional asseguradas, mas com poderes aumentados. Cf. CARvalHo, 2017, p. 281. 
buscaram fortalecer as suas correspondentes instituições ${ }^{17}$. Conscientemente, ou não, a Assembleia Nacional Constituinte imprimiu um novo projeto ao Tribunal de Contas: o exercício da fiscalização operacional. Do extenso estudo empírico realizado por ANDRÉ ROSILHO, não se constata qualquer debate substancial sobre fundamentos, limites e conteúdo desta inédita atribuição ao Tribunal de Contas ${ }^{18}$. Um simples silêncio eloquente rompeu com a tradição constitucional de prever tríplice competência fiscalizatória de contas: a "fiscalização contábil, financeira e orçamentária", tal qual o título da Seção IX. Pode-se afirmar que da Constituição de 1988 surge uma nova instituição Tribunal de Contas, tradicionalmente controladora das contas públicas, mas que passou a deter expressa capacidade de controle operacional quanto à legalidade, legitimidade, economicidade, aplicação de subvenções e renúncia de receitas, na condição de auxiliar do Congresso Nacional.

A grande inovação em sua disciplina constitucional está na inédita previsão da competência operacional no art. 70:

Art. 70. "A fiscalização contábil, financeira, orçamentária, operacional e patrimonial da União e das entidades da administração direta e indireta, quanto à legalidade, legitimidade, economicidade, aplicação das

17 IbSen Pinheiro, considerado articulador do lobby do Ministério Público na Constituinte, relata os bastidores do desenho da seção do Ministério Público, por ele considerada prenhe de privilégios e ausente de responsabilidade pelos seus membros. Indica, em sua entrevista, que a inclusão do Ministério Público de Contas foi fruto de um acordo no âmbito da Constituinte. Cf. CarvalHo, 2017, p. 365.

18 "Da leitura dos anais da ANC [Assembleia Nacional Constituinte], observase que o grau de reflexão do constituinte sobre o modelo de controle externo a ser desempenhado pelo TCU e sobre as externalidades (positivas e negativas) que as normas que delineou produziriam foi baixo. A impressão que se tem é a de que o processo de reforma das competências dos tribunais de contas foi incremental, substancialmente inspirado na prévia experiência de controle e fortemente influenciado por atores externos à ANC (especialmente pelas próprias cortes de contas)". RosiLHo, 2016, p. 76-77. 
subvenções e renúncia de receitas, será exercida pelo Congresso Nacional, mediante controle externo, e pelo sistema de controle interno de cada Poder". Destacamos.

Art. 71. "O controle externo, a cargo do Congresso Nacional, será exercido com o auxílio do Tribunal de Contas da União, ao qual compete:

IV - realizar, por iniciativa própria, da Câmara dos Deputados, do Senado Federal, de Comissão técnica ou de inquérito, inspeções e auditorias de natureza contábil, financeira, orçamentária, operacional e patrimonial, nas unidades administrativas dos Poderes Legislativo, Executivo e Judiciário, e demais entidades referidas no inciso II;". Destacamos.

Tampouco a Assembleia Nacional Constituinte teve a oportunidade de debater a extensão, os limites e o significado institucional da "ressignificação" do Tribunal de Contas para a fiscalização operacional. Os dois grandes personagens dessa pesquisa são estranhos desconhecidos da Assembleia Nacional Constituinte.

\section{Vida que segue: $O$ Tribunal de Contas cons- truiu sentidos ao controle operacional}

Com a definição do controle operacional na Constituição Federal e a ausência de leis que o conformassem, os Tribunais de Contas aproveitaram o "vácuo normativo" para construírem a prática do controle operacional. Isso se deu fundamentalmente por meio da consolidação de entendimentos internos sedimentados a partir do acúmulo de experiência concreta. No caso do TCU, guias orientativos internacionais foram decisivos ao desenho dos padrões de controle operacional, a exemplo da International Organization of Supreme Audit Institutions (Intosai). De um modo geral, na esfera estadual os Tribunais de Contas mantiveram-se centrados nas suas competências tradicionais (controle 
patrimonial, orçamentário e financeiro). Nessa instância, o controle operacional é praticamente inexistente, de baixa utilização ou apenas recentemente aperfeiçoado. Portanto, o desenvolvimento da técnica de controle operacional no Brasil teve como grande protagonista o TCU.

Em 1990, o TCU editou a Portaria n. ${ }^{\circ}$ 99/90 aprovando as normas gerais para realização de auditoria operacional e seus anexos ${ }^{19}$. Essa foi a primeira normativa visando disciplinar a então nova competência constitucional de controle operacional. No ano seguinte, o TCU editou a Resolução n. ${ }^{\circ}$ 256/91 para dispor sobre o exercício da fiscalização operacional, assim definindo o seu escopo:

Art. $2^{\circ}$. "A análise de natureza operacional, a ser realizada sem prejuízo do exame da legalidade, implica na avaliação do cumprimento dos programas de governo e do desempenho das unidades e entidades jurisdicionadas ao Tribunal no tocante aos seus objetivos, metas e prioridades, bem como quanto à alocação e uso dos recursos disponíveis, inclusive os provenientes de financiamento externo". Destacamos.

A Resolução TCU n. ${ }^{\circ}$ 256/91 prevê o dever de regulamentar o procedimento (etapas de planejamento, execução e relatórios) à Presidência do Tribunal. Também estabelece o dever de órgãos e entes administrativos fixarem "em indicadores de desempenho (...) os critérios de avaliação que possibilitem o acompanhamento fisico-financeiro dos programas governamentais e a análise (...)"20. Trata-se de uma "norma sem dentes", pois não especifica qualquer consequência jurídica ao controlado ou mesmo reconhece prerrogativas sancionatórias ao TCU. As seguintes características conformam a Resolução TCU n. ${ }^{\circ}$

19 Por sua vez, veiculados ao Boletim do TCU n. 57/1990. Infelizmente não foi possível acessar o documento eletronicamente, dado que o repositório na página institucional contém boletins emitidos apenas a partir de 2008. Disponível em: https://portal.tcu.gov.br/transparencia/btcu/boletins/ list-pagination/2.htm. Acesso em 14 de abril de 2018.

20 Cf. art. $3^{\circ}$, Resolução TCU n. ${ }^{\circ}$ 256/91. 
256/91: (i) discricionariedade na inclusão de programas governamentais no rol de auditoria, conforme fatos ou ocorrências justificadoras para a realização da auditoria; (ii) previsão de esforços de coordenação entre as instituições controladoras; $\mathrm{e}$ (iii) valorização das escolhas administrativas na medida em que a norma prestigia o processo de formação do programa de governo e sua motivação.

Editada em 1992, a Lei Orgânica do TCU (LOTCU - Lei n. $\left.{ }^{\circ} 8.443 / 92\right)$ não disciplinou o processo de controle operacional, como deveria ser o papel da lei. Ela deveria ter disposto sobre o procedimento de controle operacional, com a previsão taxativa das prerrogativas públicas do TCU em consonância com a Constituição, garantias dos auditados, disciplina específica da decisão de natureza operacional - restrita às recomendações, ao nosso ver -, bem como a abrangência e o limite às auditorias operacionais. A LOTCU não o fez, mas previu os dentes ao controle operacional, ao atribuir poderes ao órgão para fazer seu controle operacional ser mandatório e prenhe de consequências

O poder de aplicar sanções está previsto no art. 71, inc. VIII, da Constituição Federal, limitado aos casos de ilegalidade de despesa ou de irregularidade de contas ${ }^{21}$. Apesar da expressa limitação constitucional à competência sancionatória detida pelos Tribunais de Contas, a LOTCU a expandiu para o controle operacional:

“Art. 58. O Tribunal poderá aplicar multa de Cr\$42.000.000,00 (quarenta e dois milhões de cruzeiros), ou valor equivalente em outra moeda que venha a ser adotada como moeda nacional, aos responsáveis por:

21 É o texto do art. 71, inc. VIII, da Constituição Federal: "art. 71. O controle externo, a cargo do Congresso Nacional, será exercido com o auxílio do Tribunal de Contas da União, ao qual compete: (...) VIII -aplicar aos responsáveis, em caso de ilegalidade de despesa ou irregularidade de contas, as sanções previstas em lei, que estabelecerá, entre outras cominações, multa proporcional ao dano causado ao erário;". 


\section{(...)}

II - ato praticado com grave infração à norma legal ou regulamentar de natureza contábil, financeira, orçamentária, operacional e patrimonial. Destacamos.

Desse modo, o gestor público que desempenhe a competência legal poderá ser apenado com multa em uma auditoria ou inspeção de controle operacional, por exemplo, se o TCU julgar ter ocorrido infração grave de ordem operacional. A LOTCU é omissa quanto à delimitação dos contornos do controle operacional. $\mathrm{O}$ mesmo se verifica com relação à sanção de inabilitação aos cargos em comissão ou funções de confiança, não prevista na Constituição, mas passível de ser aplicada em caso de "irregularidades constatadas", desde que graves e decididas por maioria absoluta dos Ministros, nos termos do art. 60 da LOTCU. A abertura semântica de "irregularidades" permite interpretação ampla para abarcar irregularidades de qualquer natureza sob competência do TCU, inclusive irregularidades operacionais. Ainda, a LOTCU determina que as contas serão julgadas irregulares quando implicarem em " prática de ato de gestão ilegal, ilegítimo, antieconômico, ou infração à norma legal ou regulamentar de natureza contábil, financeira, orçamentária, operacional ou patrimonial" 22 .

É possível depreender que a Lei vislumbrou a determinação de vários dos seus preceitos - não endereçados ou insuficientemente legislados - pelo próprio TCU, conferindo-lhe esse papel de construção da dinâmica do controle patrimonial, financeiro, orçamentário e operacional ${ }^{23}$.

22 Cf. art. 16, inc. III, $b$, e art. 58, inc. II, da Lei n. ${ }^{\text {o }}$ 8.443/92.

23 Sobre a construção do conteúdo da lei a partir de jogos políticos externos ao Poder Legislativo, cf. André CYrINo, Como se Fazem as Leis? Democracia, grupos de interesse e controle de constitucionalidade in Revista Brasileira de Estudos Políticos, vol. 113. Belo Horizonte, jul./dez. 2016. 
Por um lado, a LOTCU apresenta diversas delegações normativas, incumbindo ao Regimento Interno disciplinar o processo de aplicação de sanções aos administradores ou responsáveis (art. 56) e o ônus de disciplinar a gradação das multas (art. 59, $\left.\$ 3^{\circ}\right)$, por exemplo ${ }^{24}$. Por outro, a LOTCU atribuiu poder regulamentar expresso ao TCU para editar "atos e instruções normativas sobre matéria de suas atribuições e sobre a organização dos processos que lhe devam ser submetidos" (art. $\left.3^{\circ}\right)$. Ao contrário do Conselho Nacional de Justiça $(\mathrm{CNJ})^{25} \mathrm{e}$ do Conselho Nacional do Ministério Público (CNMP) ${ }^{26}$, a Constituição não atribui competência normativa ao TCU.

A lacuna legislativa, associada à cultura institucional de valorização do controle operacional, possibilitou que o próprio TCU normatizasse o controle operacional a partir da experiência prática, cada vez mais intensa ${ }^{27}$.

24 Ao todo, a LOTCU traz 52 delegações normativas expressas ao Regimento Interno.

25 É a redação do art. $103-\mathrm{B}, \S 4^{\circ}$, inc. I: " $\$ 4^{\circ}$. Compete ao Conselho o controle da atuação administrativa e financeira do Poder Judiciário e do cumprimento dos deveres funcionais dos juízes, cabendo-lhe, além de outras atribuições que lhe forem conferidas pelo Estatuto da Magistratura: I - zelar pela autonomia do Poder Judiciário e pelo cumprimento do Estatuto da Magistratura, podendo expedir atos regulamentares, no âmbito de sua competência, ou recomendar providências". Destacamos.

26 É a redação do art. $130-\mathrm{A}, \S 2^{\circ}$, inc. I: " $\$ 2^{\circ}$ Compete ao Conselho Nacional do Ministério Público o controle da atuação administrativa e financeira do Ministério Público e do cumprimento dos deveres funcionais de seus membros, cabendo lhe: I zelar pela autonomia funcional e administrativa do Ministério Público, podendo expedir atos regulamentares, no âmbito de sua competência, ou recomendar providências". Destacamos.

27 Cf. Manual de Auditoria Operacional, 2010, p. 9. Consta da Apresentação da Portaria n. ${ }^{\circ}$ 12/2002 a seguinte passagem: "[a]s auditorias de natureza operacional - ANOp, tanto na modalidade de desempenho operacional quanto na de avaliação de programa, têm se disseminado cada vez mais no âmbito do Tribunal de Contas da União. Esse fato significa o reconhecimento da importância de se avaliar não apenas os aspectos relativos à legalidade, mas também aqueles atinentes à economicidade, eficiência, eficácia, efetividade e eqüidade das despesas governamentais". Destacamos. Na esfera acadêmica, 
Assim, o controle operacional foi construído jurisprudencialmente. A partir de casos concretos, o TCU delimitou a dinâmica do controle operacional: fundamentos, métodos, limites, interpretações e cominações. A primeira consolidação dessa experiência se deu com a elaboração do Manual de Auditoria de Desempenho, em 1998, por meio do qual foram reunidos os procedimentos operacionais e as estratégias metodológicas para a realização de auditorias operacionais e avaliações de programa ${ }^{28}$. O Manual foi revisto em 2000 e, pela Portaria 144/2000, passou a ser denominado Manual de Auditoria Operacional e teve seu conteúdo reformulado. O documento tem como destinatário primeiro o corpo técnico do $\mathrm{TCU}^{29}$ e a sua redação não apresenta o "vernáculo

e especificamente no controle das atividades das Agências Reguladoras, BENJAMIN ZyMLER confirma o diagnóstico: "[e] $m$ face das perspectivas de ampliação das demandas de controle nessa área, está-se iniciando um projeto com vistas a ampliar e consolidar a capacidade operacional do Tribunal de Contas da União para realizar trabalhos de controle externo na área de regulação de serviços públicos objeto de delegação". Cf. ZYMLER, 2002, passim.

28 Cf. art. $1^{\circ}$ da Portaria TCU n. ${ }^{\circ} 222 / 98$, com conteúdo veiculado pelo Boletim do TCU n. ${ }^{\circ}$ 37/2000. Infelizmente não foi possível acessar o documento eletronicamente, dado que o repositório na página institucional contém boletins emitidos apenas a partir de 2008. Disponível em: https://portal. tcu.gov.br/transparencia/btcu/boletins/list-pagination/2.htm. Acesso em 14 de abril de 2018.

29 A revisão do Manual decorre de uma necessidade interna de padronização dos processos de controle operacional praticados no âmbito do TCU, vinculando seu corpo técnico como um todo. Não por outra razão o art. $3^{\circ}$ da Portaria 144/2000 estabelecer que "[t]odas as auditorias operacionais realizadas por este Tribunal deverão observar o disposto neste manual". Nessa linha, seus "considerandos" indicam que a Portaria 144/2000 atende a determinação do Plenário do TCU à Segex para adoção de manuais: "[c] onsiderando o item 9.5 do Acórdão 2.730/2009 TCU-Plenário, que determina à Secretaria-geral de Controle Externo orientar suas unidades técnicas acerca da necessidade de as auditorias operacionais observarem o disposto nos manuais, roteiros e técnicas aprovados pelo Tribunal; Considerando a necessidade de adaptação do Manual à evolução dos métodos e técnicas empregados pelo TCU na realização de auditorias operacionais;". 
normativo" típico das normas, sem versar sobre limites, direitos e garantias dos auditados. O Manual se encontra em sua $3^{\text {a }}$ edição. ${ }^{30}$

O Manual de Auditoria Operacional define o escopo de abrangência do controle operacional de modo amplo, com base nos princípios constitucionais de controle dos Tribunais de Contas (economicidade, eficiência, eficácia e efetividade). Além dessas, reconhece "outras dimensões de desempenho" em função de sua "relevância para a delimitação do escopo das auditorias operacionais":

"Aspectos como a qualidade dos serviços, o grau de adequação dos resultados dos programas às necessidades das clientelas (geração de valor público), equidade na distribuição de bens e serviços podem ser tratados em auditorias operacionais com o objetivo de subsidiar a accountability de desempenho da ação governamental" 31 .

O sentido de controle operacional atribuído pelo TCU é amplo, imiscuindo sobre as decisões de gestão pública ou, por outra perspectiva, sobre as atividades-fim da Administração Pública. Como nota peculiar frente às "auditorias de regularidade", o Manual indica que as "auditorias operacionais" possuem maior flexibilidade quanto à escolha de temas, métodos e forma de comunicar as conclusões alcançadas $^{32}$. O ponto alto do documento diz respeito ao "ciclo de auditoria operacional", em que as fases do processo de controle operacional são especificadas: seleção, planejamento, execução, relatório, comentário do gestor, apreciação, divulgação e monitoramento.

30 Disponível em: https://portal.tcu.gov.br/controle-externo/normas-eorientacoes/normas-tcu/auditoria-operacional.htm. Acesso em 14 de abril de 2018.

31 Manual de Auditoria Operacional, 2010, p. 12.

32 Idem, p. 13. 
O Manual de Auditoria Operacional reconhece a subjetividade no controle operacional ${ }^{33}$. Para a presente análise, este é um ponto relevante na medida em que temos por objeto de estudo o diálogo institucional entre Agências Reguladoras e TCU, que se estabelece em torno da interpretação e da aplicação concreta de normas finalísticas, ensejando importante reflexão sobre a legalidade e a legitimidade de determinações e de recomendações no controle operacional.

Outro aspecto relevante diz respeito à disciplina do "achado de auditoria", alcançado a partir da aplicação do "critério de auditoria" sobre o objeto de controle ${ }^{34}$. Por sua vez, o critério de auditoria corresponde ao padrão de desempenho determinado unilateralmente pelo controlador que permita medir a economicidade, a eficiência, a eficácia e a efetividade da atividade fiscalizada ${ }^{35}$. Na tentativa de conferir direcionamento mais específico, tentou-se parametrizar o que seria desempenho satisfatório: "não éo desempenho perfeito, mas éo esperado, considerando as circunstâncias com as quais o auditado trabalha"36. Percebe-se, aqui, uma preocupação análoga ao art. 22 da Nova LINDB de considerar os obstáculos reais do gestor, mas inexoravelmente resulta no deslocamento das competências finalísticas de gestão pública ao controlador.

Muito embora o Manual de Auditoria Operacional seja o veículo de normatização mais relevante no âmbito do TCU,

33 "Pela sua natureza, as auditorias operacionais são mais abertas a julgamentos e interpretações e seus relatórios, consequentemente, são mais analíticos e argumentativos". Idem, p. 13-14. Ainda, "[e]nquanto nas auditorias de regularidade o exame da materialidade está diretamente relacionado ao montante de recursos envolvidos, nas auditorias operacionais essa é uma questão mais subjetivae pode basear-se em considerações sobre a natureza ou o contex to do objeto auditado". Idem, p. 14.

34 Idem, p. 35.

35 Idem, ibidem.

36 Idem, ibidem. 
outras normas foram editadas para detalhar procedimentos específicos. Em 2002, por exemplo, foi editada a Portaria Segecex 12/2002 para aprovar o roteiro para monitoramento de auditorias de natureza operacional. Na prática, o Roteiro de Auditoria: Monitoramento de Auditorias de Natureza Operacional termina por disciplinar o diálogo institucional entre TCU e o órgão controlado, estabelecido com a decisão de controle operacional por meio do monitoramento. Os seguintes pressupostos podem ser depreendidos do roteiro apresentado:

a) Dever de endereçamento das determinações e das recomendações. $\mathrm{O}$ Roteiro não faz qualquer diferenciação entre determinações e recomendações, as quais devem obrigatoriamente ser acatadas pelo gestor público pela elaboração de um Plano de Ação, com definição de prazos para apresentação de relatórios parciais de monitoramento e indicação dos "benefícios efetivos" pela implementação das recomendações do TCU, tais como impactos financeiros e qualitativos ${ }^{37}$. É importante lembrar que a Lei não prevê expressamente a figura das recomendações e nem estabelece que as mesmas devem ser obrigatoriamente acatadas pelos controlados.

b) A interpretação do controlador é sempre acertada e sempre benéfica ao funcionamento da máquina administrativa. Não se verifica qualquer indicativo de que a Administração Pública possa, fundamentadamente, afastar recomendações porque digam

37 Um dos itens do Relatório de Impacto de Auditoria, elaborado pelo controlador ao final do processo, corresponde à análise da implementação das recomendações, assim especificada: "[n]esse item, apresentam-se, para cada recomendação, o grau de implementação e o impacto decorrente, identificado de acordo com o item 2.4 deste roteiro. Se o número de recomendações for muito grande, recomenda-se, conforme mencionado no item 2.3, destacar as principais e analisar as restantes em conjunto. Sempre que possível, a equipe deve quantificar os impactos resultantes da implementação das recomendações, especificando os cálculos desenvolvidos para a apuração dos benefícios alcançados, sejam eles financeiros ou não. Em qualquer caso, os valores finais e a forma de mensuração devem ser apresentados ao gestor para validação". Destacamos. Portaria TCU 12/2002, Roteiro para Monitoramento de Auditorias de Natureza Operacional, p.15. 
respeito, por exemplo, ao mérito da decisão administrativa ou simplesmente porque a recomendação dada não é a melhor alternativa, na visão do gestor público que detém a competência legal para decidir. Há simplesmente uma possibilidade de o gestor apresentar sugestões ao relatório de impacto de auditoria ao término do processo de monitoramento, caso o controlador entenda por bem circular sua versão preliminar, o que não altera esse panorama. O Roteiro apresenta como variável fixa da análise de monitoramento os "benefícios obtidos" e estipula a confecção de Relatório de Impacto de Auditoria ao final do processo com "o objetivo de relatar, sinteticamente, os resultados alcançados com a implementação das recomendações do TCU"38.

Reforça-se que a Lei não prevê as recomendações e não apresenta qualquer obrigação de acatá-las pelo gestor público. No entanto, como será oportunamente demonstrado, a presente pesquisa constata uma via de mão dupla no reconhecimento de enforcement às determinações e recomendações controladoras: TCU emite determinações e recomendações na expectativa de que ambas sejam cumpridas, e requer a demonstração cabal de seu cumprimento pelo gestor, e as Agências Reguladoras espontaneamente as acatam.

Muito embora a LOTCU não disponha sobre as recomendações, que seriam típicas manifestações em controles operacionais, elas terminam por ensejarem observância pelos seus destinatários pelo simples fato de serem produto decisório do Tribunal. Assim, desatender injustificadamente diligência do Relator ou da decisão do Tribunal enseja aplicação de multa (art. 58, inc. IV), assim como na hipótese de deixar de dar cumprimento à decisão do Tribunal, salvo por motivo justificado $\left(\operatorname{art} .58, \$ 1^{\circ}\right)$. Com relação à produção normativa, o art. $3^{\circ}$ da LOTCU estabeleceu mecanismo de

38 Idem, p. 10. 
vinculatividade ao determinar a pena de responsabilidade àquele que não cumprir com suas instruções normativas e demais atos regulamentares.

No âmbito interno do TCU, essa diretriz geral de observância das decisões controladoras, ainda que referentes a atividade operacional, materializou-se nas normativas e entendimentos referentes ao controle operacional. No Roteiro para Monitoramento de Auditorias de Natureza Operacional, por exemplo, o cumprimento das recomendações é uma variável de análise a ser considerada pela unidade técnica do TCU:

"Análise da implementação das recomendações - nesse item, apresentam-se, para cada recomendação, o grau de implementação e o impacto decorrente, identificado de acordo com o item 2.4 deste roteiro. Se o número de recomendações for muito grande, recomenda-se, conforme mencionado no item 2.3, destacar as principais e analisar as restantes em conjunto. Sempre que possivel, a equipe deve quantificar os impactos resultantes da implementação das recomendações, especificando os cálculos desenvolvidos para a apuração dos benefícios alcançados, sejam eles financeiros ou não. Em qualquer caso, os valores finais e a forma de mensuração devem ser apresentados ao gestor para validação" ${ }^{\prime \prime 3}$. Destacamos.

Desse modo, as normas disciplinam o dever de implementação das recomendações controladoras. Em um cenário de incremento da reputação institucional dos controladores e de temor na tomada de decisão pública ${ }^{40}$, é natural que se estabeleça entre TCU e Administração Pública um diálogo

39 Roteiro de Auditoria: Monitoramento de auditorias de natureza operacional, 2002, p. 15.

40 Esse é o diagnóstico apresentado por uma linha de autores e pesquisadores de "apagão das canetas", em que as autoridades públicas competentes receiam tomar decisões pelo risco de serem responsabilizados "com o seu próprio $C P F^{\prime \prime}$ se os controladores entenderem que a decisão pública é ilegal, ainda que ausente má-fé, ainda que a decisão controladora se apoie em princípios. O problema foi endereçado 
institucional de comando e não uma relação dialógica horizontal.

A normatividade do Manual de Auditoria Operacional e do Roteiro de Auditoria: Monitoramento de Auditorias de Natureza Operacional foi reforçada com o Acórdão 2.730/2009, que determinou à Secretaria-Geral de Controle Externo a observância dos manuais, roteiros e técnicas aprovadas pelo Tribunal em suas auditorias operacionais.

Para fins de consolidação desse conjunto normativo, foram editadas Portarias de consolidação da experiência concreta das unidades técnicas com o controle operacional $^{41}$. Assim, por exemplo, menciona-se a Portaria 165/2004, que dispõe sobre o roteiro para elaboração de relatórios de auditoria de natureza operacional. A Portaria Segecex 27/2009 disciplina a verificação do cumprimento das determinações e recomendações expedidas pelo TCU e aprova o documento Padrões de Monitoramento.

Desde a Constituição até hoje ${ }^{42}$, o TCU tem construído unilateral e isoladamente o sentido, alcance, abrangência,

41 "Trata-se de roteiro para elaboração de relatórios de planejamento e relatórios finais de auditorias de natureza operacional e reflete o amadurecimento que seu uso proporcionou às equipes de auditoria. Este documento é produto da experiência da Secretaria de Fiscalização e Avaliação de Programas de Governo - Seprog e do Projeto Aperfeiçoamento do Controle Externo com Foco na Redução da Desigualdade Social (Cerds), sucessor do Projeto de Cooperação Técnica do TCU com o Reino Unido. Na elaboração deste roteiro, a Seprog contou com a colaboração de analistas de diversas unidades técnicas do Tribunal que participam do Projeto Cerds. Os padrões de elaboração de relatórios aqui apresentados foram testados com sucesso durante as auditorias realizadas nos últimos três anos e complementam informações contidas no Manual de Auditoria de Natureza Operacional do TCU. Espera-se que a disseminação desses padrões entre o corpo técnico contribua para a promoção da qualidade dos relatórios, para a definição de uma identidade gráfica institucional e para simplificar, com ganho de tempo, a elaboração dos documentos". Destacamos. Apresentação da Portaria TCU 165/2004.

42 Cf. Portaria 144/2018, que dispõe sobre a priorização da instrução de processos no âmbito da Segecex para o plano operacional 2018/2019. 
limites, prerrogativas, processos e garantias do controle operacional no lugar na legislação. Trata-se de um movimento interno do Tribunal, considerando o acúmulo de experiência com a realização concreta do controle operacional. Vale ressaltar que as normas editadas pelo Tribunal não são precedidas de processo normativo com avaliação de impacto ou abertura ao diálogo dos interessados e da sociedade em geral por meio de audiências e consultas públicas. O conjunto de normas, técnicas e orientações viabilizam a substituição da interpretação administrativa pela interpretação controladora no exercício da função pública, conferindo, ainda, enforcement a esta.

\section{Um novo diálogo institucional: o controle das Agências Reguladoras pelo Tribunal de Contas}

A já complexa relação de controle da Administração Pública pelo Tribunal de Contas, notadamente no controle de caráter operacional, ganha patamares de ainda maior complexidade quando a instituição controlada detém natureza especial. Assim poderíamos listar, por exemplo, as empresas estatais não dependentes de repasses públicos, com regime jurídico empresarial derrogado pelo regime administrativo mínimo determinado no art. 37 da Constituição Federal. As mesmas dúvidas de controle se colocam com relação às Agências Reguladoras, dotadas de autonomia e de independência para regular. Mais interessante ainda é considerar que TCU com competências operacionais e Agências Reguladoras são duas instituições desconhecidas pela Assembleia Nacional Constituinte. Eis uma das principais questões jurídicas que têm animado os debates jurídicos: que controle das Agências Reguladoras pelo Tribunal de Contas o sistema jurídico brasileiro desenha? 
Pode o TCU emitir recomendações às Agências Reguladoras? E determinaçôes? Tem competência para comandar a produção de normas regulatórias? Goza de legitimidade para determinar o modo de fiscalizar as reguladas, inclusive determinando o desenvolvimento de estudos e a manutenção de banco de dados? Está a seu alcance determinar o encaminhamento periódico de relatório de desempenho em projeto desenhado pela Agência? Pode determinar a inclusão em novos contratos de cláusula que defina metodologia de cálculo de indenizações relativas a bens reversiveis, não amortizados? A Constituição Federal the confere competência para impedir assinatura de termos de ajustamento de conduta por Agência Reguladora? Pode determinar o que se deve atentar em uma fiscalização, bem como a ordem de preferência dos objetos fiscalizados? E determinar a elaboração de metodologia para reclassificação de serviços com vistas à otimização das tarifas? Seu rol de competência abarca dar ciência a Agência de que o escasso quadro de servidores da Agência em áreas chave pode comprometer a concretização dos objetivos institucionais da entidade, em afronta ao princípio constitucional da eficiência? Pode determinar que the remeta manifestação da Agência sobre a repactuação do equilibrio econômico-financeiro em contratos? E quanto à determinação de divulgação de dados e informações de contratos no site de internet da Agência?

Aqui não se discute o acerto ou desacerto dessas medidas, mas argumenta-se simplesmente que esses exemplos de controle sobre as Agências Reguladoras estão compreendidos no rol de competência constitucional do Tribunal de Contas. Embora nenhum autor afaste o controle das Agências Reguladoras pelo Tribunal de Contas, há verdadeira discordância sobre a medida desse controle, considerando o regime especial dessas entidades, que gozam de autonomia e independência para exercício da função regulatória ${ }^{43}$.

43 Bom panorama da divergência doutrinária sobre o tema é apresentado 
O grande debate pode ser sintetizado em duas chaves de análise: competência e medida do controle. Com relação à competência, teria o Tribunal de Contas ampla competência para controle dos atos regulatórios ou ele se restringiria a apenas algumas atividades da Agência? ${ }^{44}$ Há autores que se apoiam no critério da tecnicidade para defender que o controle das Agências Reguladoras pelo Tribunal de Contas se limita à função administrativa, não podendo se imiscuir sobre as suas atividades técnicas ${ }^{45}$. Em outras palavras, mas com base no mesmo raciocínio, alguns autores defendem que as atividades-fim das Agências Reguladoras não estariam albergadas no controle pelo Tribunal de Contas.

Importante corrente entende que as Agências Reguladoras se submetem ao controle pelo Tribunal de Contas de modo amplo ${ }^{46}$. Essa tese de ampla sujeição das Agências Reguladoras ao Tribunal de Contas é matizada, para outros, considerando determinados elementos. É nesse racional que se desenvolve a ideia de que o Tribunal de Contas pode

por MENDONÇA. 2012, passim.

44 Outra pergunta que se coloca corresponde à competência do Tribunal de Contas para manejar as ferramentas de fiscalização e de enforcement à luz da Constituição, a exemplo das medidas cautelares, do exame prévio de editais de licitação e da declaração de inidoneidade. Esta é uma questão mais abrangente, que se não se resume ao diálogo institucional entre Agências Reguladoras e Tribunal de Contas. Para um exemplo de aplicação concreta dessa inquietação, cf. JoRDÃo, 2014, passim.

45 "Nesse sentido, não há porque o Tribunal de Contas possuir um super poder em relação às agências. Não há que se falar em competências supervenientes e abrangentes. Pelo contrário, o Tribunal de Contas possui as suas competências e as agências reguladoras, por sua vez, também as possui. Tais competências não se sobrepõem e tem que conviver harmonicamente dentro do ordenamento jurídico pátrio, por respeito à independência dos três Poderes. Nessa linha de raciocínio, o papel do Tribunal, com relação às agências reguladoras é o mesmo que ele desempenha com relação aos demais órgãos da Administração, qual seja, fiscalizar o uso do dinheiro público. Isso se reflete nas atividades administrativas da entidade, e não nas suas atividades técnicas". GONÇALVEs NeTO, 2007, passim. 
invalidar os atos regulatórios, desde que não substitua a decisão regulatória, assim compreendida a decisão de política regulatória ${ }^{47}$.

Quanto à medida do controle, a questão que se coloca diz respeito à intensidade do controle do Tribunal de Contas sobre a regulação ou à Agência Reguladora. Mais especificamente, interessa saber se a decisão controladora do Tribunal de Contas vincula, ou não, as Agências Reguladoras. Para Carlos Ari Sundfeld e Jacintho Arruda Câmara, o controle de legalidade do Tribunal de Contas recai apenas sobre a gestão financeira em sentido amplo da Administração; sobre o restante da gestão administrativa, o Tribunal de Contas só pode fazer fiscalização operacional e emitir recomendações ${ }^{48}$.

47 "Não obstante a importância do seu papel institucional, o controle não pode acarretar a substituição da decisão regulatória pela decisão da Corte de Contas. Explica-se: a Corte de Contas, ao concluir pela violação aos princípios da legalidade, legitimidade e economicidade, deve invalidar a decisão da agência, com a fixação dos parâmetros legais que deverão ser observados, no futuro, pela agência. De fato, não compete ao Tribunal de Contas instituir a politica regulatória, mas, sim, fixar, no âmbito do controle, as balizas normativas que deverão ser observadas pelas agências". Oliveira, 2015, p. 185.

48 "Matéria regulatória decidida pela entidade não integra o objeto do exame de legalidade a ser exercido por esse órgão de controle. Sua fiscalização quanto à conformidade está circunscrita à atuação financeira (em sentido amplo); não the cabendo avaliar e revisar toda e qualquer decisão administrativa tomada pela entidade. Não foi essa a função constitucionalmente prevista para os Tribunais de Contas. O Tribunal de Contas não tem poder de revisão nos casos em que a discussão envolva questão puramente regulatória, isto é, trate da aplicação de normas legais e regulamentares que digam respeito à estrita regulação setorial. Decisão típica da atuação regulatória de organismos reguladores não pode se submeter ao crivo e revisão da autoridade controladora das contas públicas, pois isso extrapolaria suas atribuições constitucionais. Ressalte-se que não é inviável que o Tribunal de Contas faça uma análise operacional do desempenho de organismos reguladores ou mesmo da regulação por eles expedida. O Tribunal pode, de fato, avaliar se a atuação geral do organismo está proporcionando maior ou menor eficiência ao setor. Mas disso não resultará qualquer ordem às autoridades administrativas, mas sempre e só recomendações não vinculantes, isto é, contribuições críticas para ajudar no permanente processo de melhoria que a própria Administração tem de fazer de sua 
Admitindo o controle das Agências Reguladoras pelo Tribunal de Contas, José Vicente Mendonça apresenta um rol de standards para que esse controle se desenvolva com respeito às competências institucionais: (i) quanto à atividademeio, os Tribunais de Contas possuem ampla competência; (ii) quanto à atividade-fim das agências reguladoras, a motivação técnica das Agências goza de preferência prima facie; (iii) os Tribunais de Contas podem exercer controle pleno sobre vícios procedimentais e de participação; (iv) o controle é pleno nas hipóteses de clara e inequívoca omissão regulatória ou de prática de ilegalidade rigorosamente literal; e (v) os Tribunais de Contas podem apenas expedir recomendações não vinculantes na avaliação da qualidade da decisão regulatória ${ }^{49}$.

Sem esgotar todas as correntes interpretativas do debate, a nossa proposta é simplesmente elucidar a profusão de ideias sobre a relação institucional entre Agências Reguladoras e Tribunal de Contas. Embora rico, o debate jurídico é limitado. É inexorável que a definição de competências institucionais e da dinâmica de controle passe por uma ordem de interpretação subjetiva, onde estão mascaradas, no formalismo e na retórica argumentativa típica do vernáculo jurídico, predileções institucionais.

Nos círculos de debate, é comum conceber o TCU a partir de sua unidade técnica, considerada de excelente qualidade e com quadros notáveis, muito em função da remuneração dos cargos técnicos marcadamente mais elevada que a oferecida pela Administração Pública a um cargo técnico correspondente ${ }^{50}$. Não por outra razão, são recorrentes

organização e atuação". SundFELd e CÂMARA, 2018, p. 79. Cf., ainda, SundFELD, CÂmara, Monteiro e Rosilho, 2017, 869-877.

49 MEndOnÇA, 2012, passim.

50 A ADIN 2310 do Supremo Tribunal Federal, julgada em 2000, que 
os exemplos de técnicos que pedem exoneração do cargo junto a órgão ou ente da Administração Pública ao serem aprovados no concurso público do TCU ${ }^{51}$. A excelência de sua unidade técnica pesa significativamente na construção

suspendeu liminarmente a eficácia dos preceitos da Lei 9.986/2000, relativos ao regime de pessoal das Agências Reguladoras. Nesse contexto, foi editada a MP 155/2003, depois convertida na Lei 10.871/2004, para revogar os preceitos questionados pelo Supremo e disciplinar as carreiras de pessoal nas Agências Reguladoras. Ao todo, e com as alterações da Lei 12.857/2013, foram criados 37 cargos distribuídos fundamentalmente em quatro carreiras: (i) Especialista em Regulação; (ii) Técnico em Regulação; (iii) Analista Administrativo; e (iv) Técnico Administrativo. O denominador comum de atribuições do Especialista em Regulação, cargo de nível superior, congrega atividades especializadas de regulação, inspeção, fiscalização e controle da prestação de serviços públicos, quando for o caso, bem como a implementação de políticas e o desenvolvimento de pesquisas e estudos na área. Por sua vez, o Técnico em Regulação é um cargo de nível intermediário com atribuições de suporte e apoio técnico especializado às atividades de regulação, inspeção, fiscalização e controle da prestação de serviços públicos, quando for o caso, bem como à implementação de políticas e à realização de estudos e pesquisas na área. Segundo dados do Boletim Estatístico de Pessoal (BEP), n. ${ }^{\circ} 249$, de janeiro de 2017, o Especialista em Regulação tem remuneração inicial de $\mathrm{R}$ \$ 12.632,86 e remuneração final de $\mathrm{R}$ \$ 20.034,72. Por sua vez, o Técnico em Regulação tem a remuneração inicial de $\mathrm{R} \$$ 6.285,34 e a remuneração final de R\$ 10.005,88. Disponível em: http://www.planejamento.gov.br/ assuntos/gestao-publica/arquivos-e-publicacoes/BEP. Acesso em 02 de julho de 2018. O Quadro de Pessoal e o Plano de Carreira do TCU é previsto na Lei 10.356/2001, composto pelos seguintes cargos efetivos: Analista de Controle Externo (AUFC, nível superior); Técnico de Controle Externo (TEFC, nível médio) e Auxiliar de Controle Externo (nível médio). Nos cargos AUFC 1 a 13, o vencimento básico de 2018 varia de R \$ 6.322,93 a R\$ 10.095,88; a gratificação de desempenho de $\mathrm{R} \$$ 8.076,70; e a gratificação de controle externo de $\mathrm{R} \$ 8.401,28$ a $\mathrm{R} \$ 11.711,22$. O total remuneratório em 2018 varia de $\mathrm{R} \$ 20.917,87$ a R $\$ 29.952,65$. Já o TEFC 1 a 13, tem vencimento básico de 2018 de $\mathrm{R} \$ 4.553,22$ a R \$ 6.562,36; gratificação de desempenho de $\mathrm{R}$ \$ 5.249,89; e gratificação de controle de $\mathrm{R} \$ 2.231,08$ a $\mathrm{R} \$ 4.987,39$. O total remuneratório em 2018 varia de $R$ \$ 12.103,05 a $R$ \$ 16.868,49. Informações disponíveis em: https://portal.tcu.gov.br/lumis/portal/file/fileDownload. jsp?fileId=8A81881F642514C401643806581C34BA. Acesso em 02 de julho de 2018.

51 Cf. FontainHa et. al., 2014, p. 73-74. 
de uma reputação institucional positiva entre os demais agentes públicos ${ }^{52}$.

Por outro lado, a temática do combate à corrupção divide opiniões sobre o papel do controle e dos controladores. Porém, de um modo geral, as instituições que se arvoram no discurso do combate à corrupção tendem a gozar de maior reputação institucional. No caso do TCU, a qualificação de suas atividades de controle, como medidas de combate à corrupção para alcançar o seu objetivo final de aprimorar a gestão pública ${ }^{53}$, também corrobora para que ele goze de maior prestígio que a Administração Pública. Essa imagem institucional é potencializada com o simbolismo de uma "Corte" que julga a Administração Pública, embora não pertença ao Poder Judiciário e nem goze de jurisdição administrativa como o Conselho de Estado francês. O modo de divulgação dos "malfeitos" apurados também favorece à construção do prestígio do TCU, comumente com o indicativo de que "a atuação do TCU economiza [milhões / bilhões] aos cofres públicos". Essa ordem de economia tem sido referenciada como fator de justificação das medidas cautelares utilizadas e que têm suscitado uma série de questionamentos jurídicos.

52 Não, porém, que a remuneração ou a aprovação em concurso público sejam critérios determinantes à qualificação técnica. Entendemos ser este atributo mais complexo do que se supõe. A experiência de mercado, o acúmulo de trabalho com casos setoriais, o diálogo com pares em eventos temáticos e a atualização, por exemplo, são outras variáveis tão ou mais relevantes à determinação da técnica e que favorecem os técnicos de regulação das Agências.

53 "A principal missão do Tribunal de Contas da União (TCU) é aprimorar a gestão pública. Uma das formas de atingir este objetivo é por meio do combate à fraude e corrupção. A indução à melhoria nos processos internos dos órgãos públicos, por meio de fiscalizações, impacta positivamente a prevenção à corrupção ao reforçar as linhas de defesa das instituições. E mesmo a expectativa de controle gerada pela atuação do Tribunal ajuda a coibir eventuais malfeitos". Cf. http://portal.tcu. gov.br/combate-a-corrupcao/. Acesso em 24 de junho de 2016. 
Reconhecimento pelos pares de capacidade técnica superior, associação das atividades de fiscalização à agenda de combate corrupção, simbolismo de Corte e enaltecimento de suas funções ajudam a explicar a construção da reputação institucional positiva de que o TCU hoje dispõe. Então, a partir dessas considerações subjetivas, qualquer interpretação do rol de competências do art. 71 da Constituição Federal para ampliação de suas competências é viável. O foco de atenção desloca-se, então, para o Supremo Tribunal Federal, que tem a palavra final para chancelar, ou não, as interpretações constitucionais que fundamentam atividades concretas do Tribunal de Contas, mesmo que inexistente na maior parte das vezes a competência legal expressa.

\section{Considerações finais}

A complexidade do controle das Agências Reguladoras pelo TCU não pode ser atribuída unicamente ao fato de a Constituinte não ter antevisto as Agências Reguladoras ou não ter tomado adequada dimensão do quanto o TCU se transformaria com a previsão da competência operacional. Contudo, essa é uma informação relevante que ajuda a compreender os caminhos trilhados até que se alcançasse a atual dinâmica de controle, um diálogo fora do esquadro.

A disciplina constitucional é apenas um ponto de partida. Como analisado, competência e medida do controle das Agências Reguladoras pelo TCU são hoje os eixos centrais de uma discussão fundamental sobre governabilidade. Às diferentes respostas teóricas em debate contrapõem-se no que diz respeito a uma prática de deslocamento das competências regulatórias ao TCU. Amparado por considerável reputação institucional, paulatinamente o TCU construiu o conteúdo jurídico da expressão "operacional" que designa 
a competência que ineditamente lhe fora atribuída pela Constituição.

Em um tom crítico a esse deslocamento de competência das Agências Reguladoras para o TCU, à revelia do texto expresso em lei, pode-se indicar que o diálogo fora de esquadro também assume novo significado para expressar que a dinâmica de controle hoje em prática talvez não seja hoje o desenho mais eficiente ou mais favorável à governabilidade. Situando o debate nas "regras do jogo da governabilidade", três respostas normativas podem ser consideradas para aperfeiçoamento desse sistema de controle: (1) reforma constitucional para estabelecer o modo de interação entre Poderes e instituições na dinâmica do controle, o que importa não apenas no controle de contas, já que a Constituição não se ocupou em estabelecer as fronteiras do controle de um modo geral; (2) elaboração de uma nova lei orgânica do TCU, cujo processo legislativo seja democraticamente permeável e as importantes decisões sejam tomadas pelo Congresso, sem amplas delegações em branco para o próprio TCU dispor em seu Regimento Interno; e (3) orientação normativa do controle pelo TCU, normas essas que devem ser aprovadas no rito de um processo administrativo normativo orientado por análises de impacto, devida motivação e fases de audiência e consulta pública.

\section{Referências}

BARROSO, Luís Roberto. Natureza Jurídica e Funções das Agências Reguladoras de Serviços Públicos. Limites da fiscalização a ser desempenhada pelo Tribunal de Contas do Estado. In: Revista Trimestral de Direito Público, v. 25, 1999.

BINENBOJM, Gustavo. Uma Teoria do Direito Administrativo. Direitos Fundamentais, Democracia e Consitucionalização. Rio de Janeiro: Renovar, 2006. 
BRASIL, Tribunal de Contas da União. Roteiro para Monitoramento de Auditoria de Natureza Operacional, 2002. . Manual de Auditoria Operacional, $3^{\text {a }}$ ed., 2010.

CARVALHO, Alexandre Douglas Zaidan de. Juscorporativismo: os juízes e o judiciário na Assembleia Nacional Constituinte in Revista Brasileira de Estudos Políticos, vol. 114. Belo Horizonte, jan./jun. 2017.

CARVALHO, Luiz Maklouf. 1998: Segredos da Constituinte. Os vintes meses que aditaram e mudaram o Brasil. Rio de Janeiro: Record, 2017.

CYRINO, André. Como se Fazem as Leis? Democracia, grupos de interesse e controle de constitucionalidade in Revista Brasileira de Estudos Políticos, vol. 113. Belo Horizonte, jul./dez. 2016. FERNANDES, Jorge Ulisses Jacoby. Tribunal de Contas do Brasil. Jurisdição e competência. Belo Horizonte: Fórum, 2016.

FONTAINHA, Fernando de Castro; GERALDO, Pedro Heitor Barros; VERONESE, Alexandre; ALVES, Camila Souza; FIGUEIREDO, Beatriz Helena; WALDBURGER, Joana. Processos Seletivos para Contratação de Servidores Públicos. Brasil, o país dos concursos? Rio de Janeiro: FGV Direito Rio, 2014.

GOLÇALVES NETO, Luiz Alonso. O Controle da Regulação - Limites ao controle do Tribunal de Contas aos atos de Agências Reguladoras. In: Interesse Público, v. 43, 2007. JORDÃO, Eduardo. A Intervenção do TCU sobre Editais de Licitação não Publicados - controlador ou administrador? In: Revista Brasileira de Direito Público, v. 47, 2014.

MARQUES NETO, Floriano de Azevedo. Agências Reguladoras Independentes, $1^{\mathrm{a}}$ reimpressão. Belo Horizonte: Fórum, 2009. 
; PALMA, Juliana Bonacorsi de. Os sete impasses da administração pública no Brasil. In PEREZ, Marcos Augusto e SOUZA, Rodrigo Pagani de (orgs.). Controle da administração pública. Belo Horizonte: Fórum, 2017.

MONTEIRO, Vera; ROSILHO, André. Agências Reguladoras e o Controle da Regulação pelo Tribunal de Contas da União. In: PEREIRA NETO, Caio Mário da Silva; PINHEIRO, Luís Felipe. Direito da Infraestrutura, vol. 2. São Paulo: Saraiva, 2017.

OLIVEIRA, Rafael Carvalho Rezende. Agências Reguladoras, Diálogos Institucionais e Controle. In: Revista de Direito Público da Economia, v. 49, 2015.

PEREIRA NETO, Caio Mario da Silva; LANCIERI, Filippo; ADAMI, Mateus Piva. O Diálogo Institucional das Agências Reguladoras com os Poderes Executivo, Legislativo e Judiciário: Uma Proposta de Sistematização. In: SUNDFELD, Carlos Ari; ROSILHO, André (org.). Direito da Regulação e Políticas Públicas. São Paulo: Malheiros, 2014.

ROSILHO, André Janjácomo. Controle da Administração Pública pelo Tribunal de Contas da União. Tese de doutorado defendida na Faculdade de Direito da USP em 2016.

SCHUCK, Peter H., Why Government Fails so Often. And how it can do better. Princeton: Princeton University Press, 2014.

SUNDFELD, Carlos Ari. Direito Administrativo para Céticos, $2^{\mathrm{a}}$ ed. São Paulo: Malheiros, 2014.

; CÂMARA, Jacintho Arruda. O Tribunal de Contas da União e a Regulação. In: Fórum de Contratação e Gestão Pública, v. 194, 2018. 
; MONTEIRO, Vera; ROSILHO, André. O Valor das Decisões do Tribunal de Contas da União sobre Irregularidades em Contratos. In: Revista Direito GV, v. 13, 2017. ZYMLER., Benjamin. O papel do Tribunal de Contas da União no controle das Agências Reguladoras. In: Fórum Administrativo - Direito Público - FA, v. 11, 2002.

Recebido em 05/05/2019

Aprovado em 18/03/2020

Floriano de Azevedo Marques Neto

E-mail: floriano@manesco.com.br

Juliana Bonacorsi de Palma
E-mail: juliana.bpalma@gmail.com

Juliana Bonacorsi de Palma
E-mail: juliana.bpalma@gmail.com

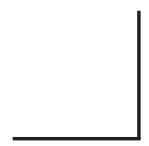

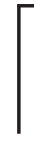

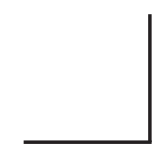

